\title{
Extracranial-intracranial bypass approach to cerebral revascularization: a historical perspective
}

\author{
Sauson Soldozy, BA, ${ }^{1}$ John S. Costello, BA, ${ }^{1}$ Pedro Norat, MD, ${ }^{1}$ Jennifer D. Sokolowski, MD, PhD, ${ }^{1}$ \\ Kamron Soldozy, ${ }^{2}$ Min S. Park, MD, ${ }^{1}$ Petr Tvrdik, PhD, ${ }^{1}$ and M. Yashar S. Kalani, MD, PhD ${ }^{1}$
}

1Department of Neurological Surgery, University of Virginia Health System, Charlottesville, Virginia; and 2Princeton Neuroscience Institute, Princeton University, Princeton, New Jersey

\begin{abstract}
While the majority of cerebral revascularization advancements were made in the last century, it is worth noting the humble beginnings of vascular surgery throughout history to appreciate its progression and application to neurovascular pathology in the modern era. Nearly 5000 years of basic human inquiry into the vasculature and its role in neurological disease has resulted in the complex neurosurgical procedures used today to save and improve lives. This paper explores the story of the extracranial-intracranial approach to cerebral revascularization.
\end{abstract}

https://thejns.org/doi/abs/10.3171/2018.11.FOCUS18527

KEYWORDS bypass surgery; cerebral revascularization; moyamoya; neurosurgical history; dissection; microsurgery; extracranial-intracranial

$\mathrm{T}$ HE first description of vascular anatomy can be found in the Ebers Papyrus, an ancient Egyptian medical document discovered dating as far back as 3000 BC. The collection of formulas and remedies includes a treatise on the heart and circulation, and it describes the paths of anatomical structures known as "met," an Egyptian word that translates into vessels. The Ebers Papyrus contains the first description of a vascular procedure in which a physician treated a bulging aneurysm with a "fireglazed" instrument. ${ }^{27}$ Indian physician Sushruta was the first to discuss the importance of hemostasis during surgery, outlining techniques to control intraoperative bleeding of vessels in his textbook published in 600 вС. $^{42}$ Further surgical recommendations were made by Hippocrates (c. $460-$ c. 370 BC) in the 4th century BC (Fig. 1), including control of hemorrhage during amputation and anatomical descriptions based on animal dissections. Hippocrates is recognized as the first to describe a clinical syndrome of "apoplexy," a sudden onset of headaches and unresponsiveness accompanied by an agape mouth among other neural deficits. Importantly, he attributed the syndrome to a direct result of arterial blockage. ${ }^{11,18}$

A student of Hippocrates' teachings, Herophilus of
Chalcedon (335-280 BC performed the first systematic human cadaveric dissections with his colleague, Erasistratus of Chios (304-250 BC), after moving to Alexandria in 300 BC..$^{59}$ Herophilus accurately described cardiovascular physiology, stating that arteries carry blood from the heart to the body and veins return blood back to the heart. In addition, he described skull base vasculature, naming the collection of vessels underneath the brain "rete mirabile," or "wonderful net." He also discovered and named the confluence of dural sinuses near the internal occipital protuberance, still known today by the eponym torcular herophili. Considered the "Father of Anatomy," Herophilus provided the first major anatomical insight of human vasculature, thus introducing the groundwork for our understanding of the circulatory system and its connection with the brain. 25,59

In AD 160, Galen of Pergamon (AD 129-199) expanded on the anatomical work of Herophilus through meticulous animal dissection. His discoveries included further description of the rete mirabile, venous sinuses, and cranial nerves. ${ }^{10}$ Galen was a prominent physician to gladiators and one of the first to practice arterial ligature as a means of hemostasis in treating injuries due to trauma. Galen also

ABBREVIATIONS CCA = common carotid artery; COSS = Carotid Occlusion Surgery Study; EC-IC = extracranial-intracranial; ELANA = excimer laser-assisted nonocclusive anastomosis; ICA = internal carotid artery; JAM = Japan Adult Moyamoya; MCA = middle cerebral artery; PICA = posterior inferior cerebellar artery; rCBF = regional cerebral blood flow; STA = superficial temporal artery; SV = saphenous vein.

SUBMITTED October 1, 2018. ACCEPTED November 26, 2018.

INCLUDE WHEN CITING DOI: 10.3171/2018.11.FOCUS18527. 


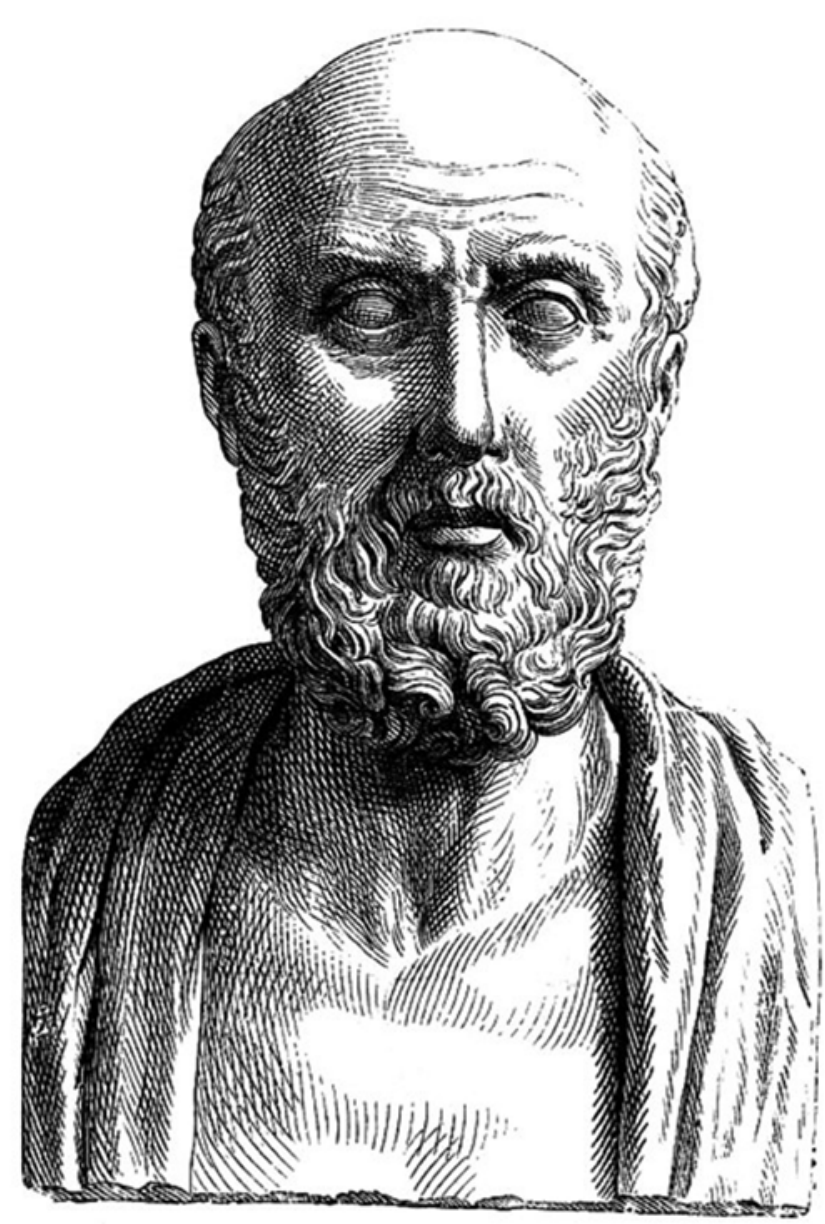

FIG. 1. Hippocrates. Public domain. Original source: Champlin JD Jr: The Young Folks Cyclopaedia of Persons and Places. New York: Henry Holt \& Co., 1891

built upon the Hippocratic concept of "apoplexy" in his writings, defining it as the sudden deprivation of sensation and motion in the body. ${ }^{11}$ In AD 200, Antyllus, a contemporary to Galen, advanced vascular surgery by performing an aneurysm repair consisting of proximal and distal ligation followed by an incision and removal of thrombotic materials. ${ }^{4}$ Approximately 100 years later, Arabian twins Cosmas and Damian were reported to have attempted the first blood vessel anastomosis during a successful limb transplant. Their patient fell ill with a gangrenous or cancerous leg, and Cosmas and Damian, initially wanting to amputate the limb, acquired a leg from a recently buried Ethiopian man and performed successful transplantation; the patient made a full recovery in "the miracle of the black leg" (Fig. 2). Though the veracity of this legend is doubtful, its existence exemplifies ancient physician confidence that vascular surgical techniques could adequately treat human disease. ${ }^{13}$

\section{Pre-Modern Era}

The surgical approaches and knowledge of vascular and neurovascular anatomy described thus far would remain largely unchanged for several hundred years during the

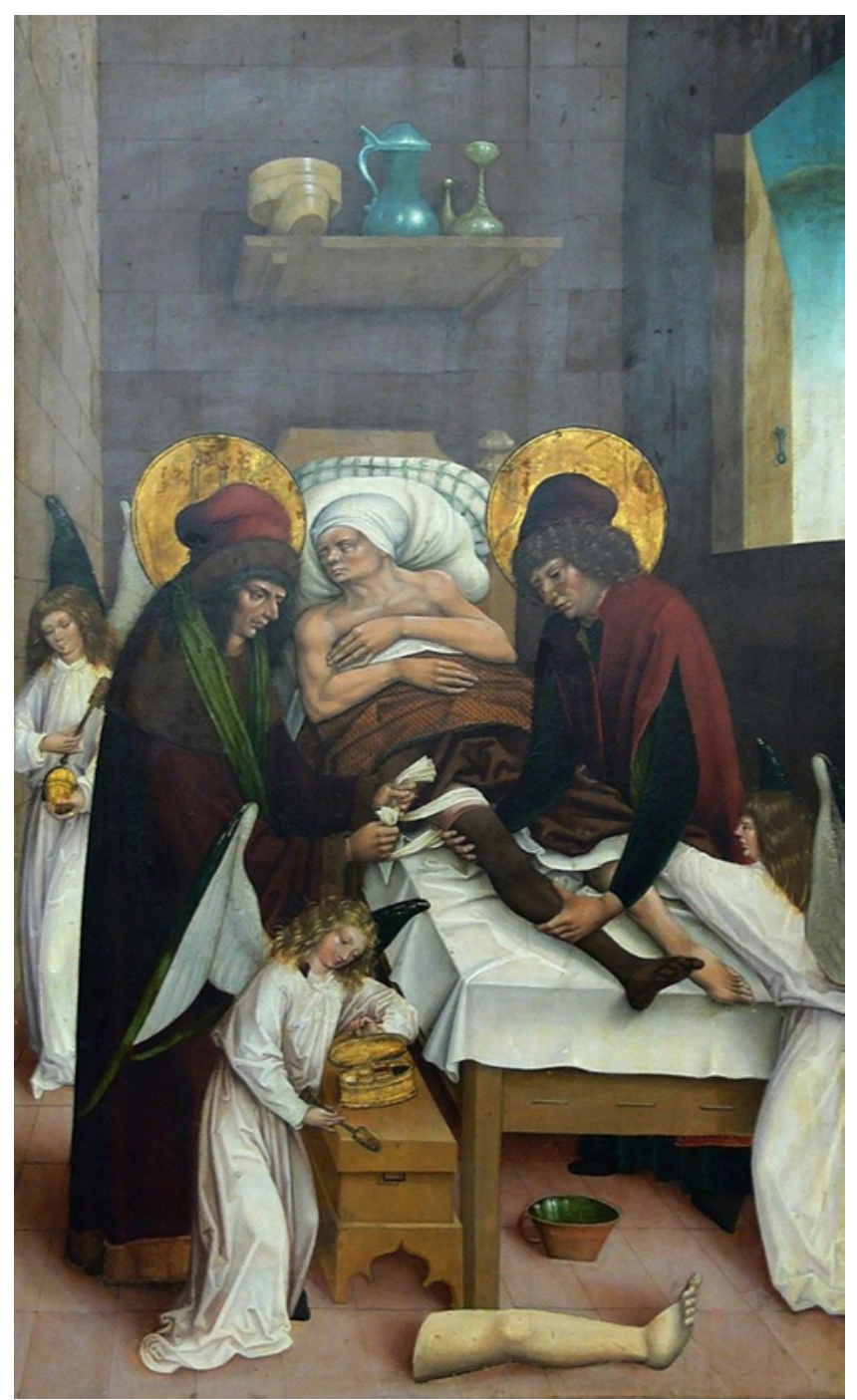

FIG. 2. Illustration of "Miracle of the Black Leg," 16th century, artist unknown. Public domain. Present location of painting: Württembergisches Landesmuseum Stuttgart.

Dark Ages. Progress was especially halted with the widespread closing of medical schools and ban on dissections by religious doctrine in the Western world, but advances continued to be made elsewhere. Persian scholars such as Rhazes (865-925) and Avicenna (980-1037) studied and improved upon the teachings of Galen using their own acquired clinical experiences. In one of his books, The Canon of Medicine, Avicenna identified neurological ailments such as central facial weakness, paralysis, and stroke. ${ }^{38} \mathrm{He}$ went on to note the importance of precision and meticulousness when making a cranial incision so as to avoid the nerves, veins, and arteries that course superficially across the skull, demonstrating a greater appreciation of the delicacy of cranial structures and understanding of brain vessel pathology than his predecessors. Another Islamic physician, Albucasis (936-1013), advocated for the use of cauterization in a wide variety of surgical procedures, including the treatment of headaches by cauterization or ligation of the superficial temporal artery (STA). 


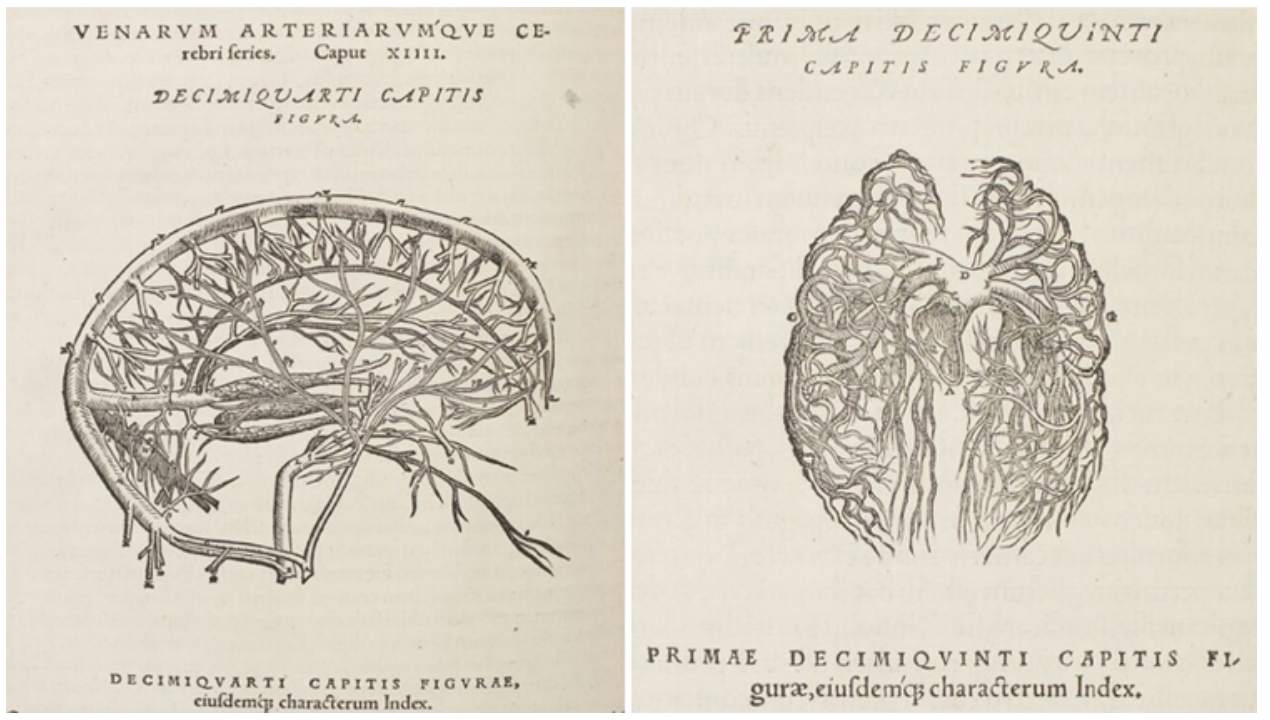

FIG. 3. Illustrations from Andreas Vesalius' work, where he depicts the vasculature of the brain. Public domain. Source: Vesalius A: De humani corporis fabrica libri septem. Basileae [Basel]: Ex officina Joannis Oporini, 1543. Image courtesy of Claude Moore Health Sciences Library, University of Virginia Health System.

By approximately AD 1000, a major step toward modern extracranial-intracranial (EC-IC) bypass surgery had taken place: blood vessel surgery involving the successful dissection and isolation of the STA.

Human dissection resumed during the European Renaissance, allowing for the publication of De humani corporis fabrica by Andreas Vesalius of Brussels in 1543. In his comprehensive work, Vesalius made corrections to more than 200 anatomical errors made by Galen and was the first to accurately depict cerebral vasculature as it exists in humans, improving upon Galen's flawed description of the rete mirabile (Fig. 3). ${ }^{25}$ It would not be until 1684 that Thomas Willis and his pupil, Christopher Wren, correctly described the "circle of Willis" in its completion as it exists in humans. Willis provided an accurate description of its connection with the carotid and vertebral arteries, a major breakthrough in the understanding of the interconnectedness of extracranial and intracranial vascular anatomy (Fig. 4). Willis directly observed the benefit of these anastomoses through experimentation involving carotid artery occlusion, noting how blood flow bypasses the region of occlusion given the presence of collateral circulation. He also described one significant case of a man with an obstructive lesion within the right carotid artery, noting how the ipsilateral vertebral artery appeared larger than that of the contralateral side, as it served as an alternate route of blood flow to prevent apoplexy. ${ }^{25}$ In 1754, less than a century after Willis' discovery, Gerhard van Swieten suggested that debris originating in the heart could break off and become lodged in distal arteries and result in apoplexy, the first proposed mechanism for cerebral embolism and stroke. ${ }^{33}$

Although significant progress was made in vascular anatomy and physiology, surgeons of the time period continued to employ the same cauterization techniques used by their predecessors to treat wounds, particularly from gunshots. French battlefield surgeon Ambroise Paré shifted the focus back toward the Galen teaching of ligature in
1564 by reporting better outcomes in comparison to cauterization in one of the first surgical clinical trials. ${ }^{17} \mathrm{~A}$ major breakthrough in the treatment of vascular wounds took place when an English physician named Hallowell performed the first documented arteriorrhaphy in 1759. Hallowell repaired a wound of the brachial artery by placing a pin through the arterial walls and elevating them in order to apply a silk suture in a figure-eight fashion. ${ }^{36}$ While this marked a transition toward more sophisticated vascular procedures, others were unable to reproduce his results, and ligation remained the primary treatment of vascular pathology for another 150 years. A breakthrough occurred in 1877 when Nicholas Eck, a Russian military surgeon,
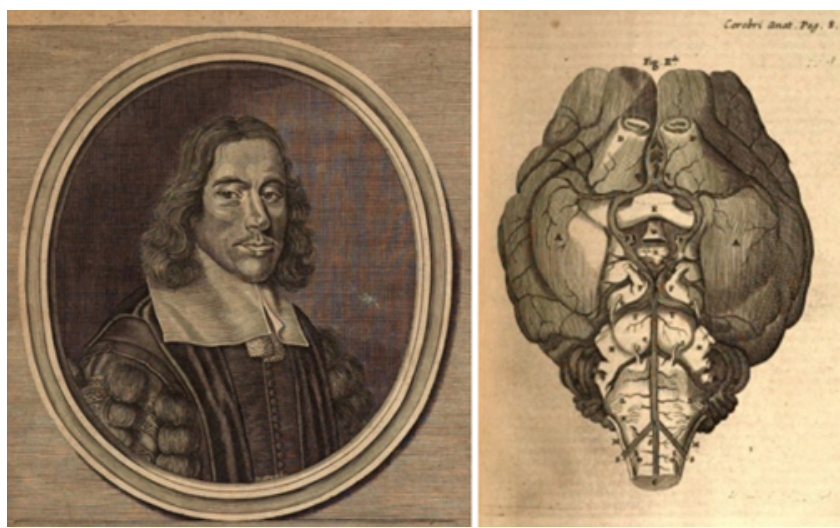

FIG. 4. Thomas Willis pictured beside the circle of Willis, illustrated by Christopher Wren in the 17th century. Public domain. Left panel source: Willis T: Opera omnia: nitidius quàm unquam hactenus edita, plurimum emendata, indicibus rerum copiosissimis, ac distinctione characterum exornata. Amstelaedami [Amsterdam]: apud Henricum Westenium, 1682. Right panel source: Willis T: Cerebri anatome: cui accessit nervorum descriptio et usus. Londini [London]: Typis Jo. Flesher, impensis J. Martyn \& Ja. Allestry apud Campanae in Coemeterio D. Pauli, M DC LXIV, 1664. Images courtesy of Claude Moore Health Sciences Library, University of Virginia Health System. 
published a canine study in which he performed a lateral anastomosis between the portal vein and inferior vena cava, known as the Eck fistula. ${ }^{49}$ Although unrecognized at the time, the Eck fistula opened the field of joining blood vessels together, thereby paving the way for modern-day cerebral bypass surgery. Another 12 years would pass until Alexander Jassinowsky in 1889 published his work on arterial sutures, describing his use of fine curved needles and fine silk interrupted sutures placed only through the adventitia and the media. ${ }^{20}$ In 1893, Robert Abbe attempted prosthetic anastomosis, in which he successfully reconnected transected canine femoral arteries utilizing glass tubes. He performed the same procedure on a feline aorta and, 4 months later, presented the cat "fat and strong" to his audience. ${ }^{29}$ Findings from these primarily animal experiments provided significant support that patent arterial surgery and repair is possible and applicable to vascular injuries and pathological processes.

\section{Transition Period}

On October 7, 1896, John Murphy of Chicago operated on a 29-year-old Italian peddler suffering from a femoral artery injury due to a groin gunshot wound. Using an invagination technique, Murphy performed the first end-toend arterial anastomosis that remained patent 3 months postoperatively. Soon after, many began to employ his anastomosis technique, marking the first formal departure away from ligature since its popularization by Galen nearly 1800 years ago. In 1899, Julius Doerfler reported several experiments that indicated penetration of the intima during full-thickness arterial repair would not necessarily lead to thrombus formation. ${ }^{3,37}$ French physician Alexis Carrel published his own work on end-to-end anastomosis in 1902, developing a triangulation technique using over-and-over running suture. After moving to the US, Carrel began working with Charles Guthrie, who helped him perfect the best approach to vessel anastomosis. Carrel is credited with being the first individual to demonstrate the use of venous patch grafts and would go on to win the Nobel Prize in Physiology or Medicine in 1912 for his work, although Guthrie was never acknowledged. ${ }^{37}$ In 1925, Weglowski of present-day Ukraine described 40 cases of successful vein grafts used to repair traumatic arterial defects in Polish and Russian soldiers during both World War I and the subsequent Polish-Bolshevik War. ${ }^{37}$ Indirect cerebral revascularization surgery began in 1939 when German and Taffel transposed vascular muscle flaps onto the cortex of primates and dogs, documenting the first encephalomyosynangiosis. This procedure was later attempted in humans 3 years later, but it was halted due to the high incidence of seizures. ${ }^{16}$

These surgical developments were accompanied by advancements in imaging techniques, beginning with the development of cerebral angiography by Egas Moniz in 1927. After experimenting with various radiopaque agents, Moniz utilized sodium iodide as a rapidly infusing, optimally enhanced, and biologically safe contrast to visualize structures within the brain. He received three Nobel Prize nominations for his work $(1928,1932$, and 1937) and ultimately won in 1949 with his colleague Walter Rudolf Hess for unrelated work on prefrontal leucotomy. ${ }^{2}$ Neurovascular imaging allowed for the visual confirmation of several pathologic processes, including the link between carotid occlusion and cerebral infarction, as described by Hans Chiari in $1905 .{ }^{33}$ In 1951, Miller Fisher (1913-2012) not only confirmed Chiari's work but also was able to define the varying degrees of carotid stenosis and their clinical consequences, including "transient global amnesia," "ocular bobbing," "wrong-way eyes," "string sign," and more. .32 He believed that a surgical solution to the identified pathology was feasible and famously stated, "It is even conceivable that some day vascular surgery will find a way to by-pass the occluded portion of the artery during the period of ominous fleeting symptoms." 12

In 1953, Michael Debakey would successfully combine Fisher's wisdom with the vascular techniques of his time and perform the first carotid endarterectomy. ${ }^{52}$ Four years later, surgeons Champ Lyons and Garber Galbraith reported the utilization of a subclavian-to-internal carotid artery (ICA) prosthesis bypass. An end-to-side suture of the nylon shunt to the subclavian artery was performed, and the shunt was tunneled under the sternocleidomastoid and sutured end-to-side into the ICA. ${ }^{28}$ As more surgeons mastered blood vessel reconstruction surgery and bypass procedures, research focuses shifted toward microsurgery and utilization of the operating microscope. Originally introduced in 1922 by Swedish otologist Carl Olof Nylén, the operating microscope helped debunk the prevailing thought of the 1950s that anastomosis on vessels less than 5 or $6 \mathrm{~mm}$ in diameter was not feasible. ${ }^{34}$

\section{Modern Era}

The operating microscope was first used in neurosurgery by Theodore Kurze at the University of Southern California in 1957, where it aided in removal of a schwannoma from a 5-year-old patient's facial nerve. ${ }^{54}$ This instrument's critical transition into neurovascular microsurgery would occur a year later at the University of Vermont, where Raymond Donaghy and his colleague Julius Jacobson established the world's first microsurgery training and research laboratory. In 1960, they, along with their resident Martin Flanagan, performed a middle cerebral artery (MCA) embolectomy in the first microvascular neurosurgical procedure ever performed on a human patient. ${ }^{24}$ Of the 9 patients they eventually operated on, only 2 had MCAs that remained patent, in stark contrast to animal laboratory results; Jacobson and his colleague E. Suarez reported $100 \%$ patency of carotid artery anastomosis at 4 months in experiments performed on 6 rabbits and 20 dogs. ${ }^{19}$ Cerebral revascularization was attempted with a synthetic graft by J. Lawrence Pool and D. Gordon Potts in 1961. They created a shunt using a plastic tube between the STA and anterior cerebral artery, although arteriography showed the tube to be clotted postoperatively. ${ }^{8}$ In 1963, Woringer and Kunlin performed the first EC-IC bypass between the common carotid artery (CCA) and ICA, utilizing a saphenous vein (SV) graft and the suspended suture technique. Unfortunately, the patient did not survive despite the graft being patent on autopsy. ${ }^{53}$

Mahmut Gazi Yaşargil, a Turkish physician at the time 
working in Zurich, became aware of the procedure carried out by Woringer and Kunlin, sparking his profound interest in cerebral revascularization. When Yaşargil was presented a case in 1963 involving a 17-year-old girl with right-sided hemisyndrome due to an occluded left central sulcus artery, he declined to operate due to lack of laboratory experience with microvascular surgery, prompting his desire to practice microneurosurgery techniques in a laboratory. He began training with Donaghy in 1965, and, within his first 4 weeks there, performed patch, end-toend, end-to-side, graft insertion, and duplication procedures on the femoral, radial, and ulnar arteries and aortas of rabbits..$^{60}$ The dissection and repair of intracranial vessels was made more feasible by the introduction of 9-0 suture and utilization of the bipolar coagulator in 1966.57 Electric cautery in neurosurgery was initially pioneered by Harvey Cushing in 1926, who, working with William Bovie, was able to remove the remnants of a vascular sarcoma that was otherwise unable to be resected due to excessive bleeding. ${ }^{6,58}$ James Greenwood introduced the concept of two-point or bipolar coagulation in 1940, and Leonard Malis designed the version used by Yaşargil (and by many neurosurgeons today) in $1955 .{ }^{6}$ Given these precision surgical tools at his disposal, Yaşargil began attempts at high-flow graft bypasses between common carotid and basilar or middle cerebral arteries. The attempts failed due to thrombosis of the arterial and venous grafts he was using, prompting his pioneering decision to forgo the use of grafts and instead directly join the STA to the MCA. By the end of 1966, he performed more than 30 end-to-side STA-MCA anastomoses in canines, all of which remained patent ${ }^{60}$ On October 30, 1967, Yaşargil implemented his technique for the first time on a patient with Marfan syndrome with complete occlusion of the MCA, creating a feasible EC-IC bypass approach for cerebral revascularization that would revolutionize reconstructive intracranial vascular microsurgery. ${ }^{57}$

Throughout the 1970s, different approaches to EC-IC bypass were explored while the STA-MCA procedure was further studied and optimized. For example, in 1971, William Lougheed performed EC-IC bypass on a 54-year-old woman with complete occlusion of the right ICA. In this procedure, Lougheed anastomosed an SV bypass graft between the CCA and intracranial ICA, noting how this method supplies greater amounts of blood when compared to Yaşargil's method. ${ }^{26}$ In 1972, Yaşargil applied STAMCA bypass to moyamoya disease for the first time, with patency being maintained 2 years later on angiography. ${ }^{16}$ STA-MCA bypass continues to be the preferred treatment for moyamoya disease today given its excellent patency rates and symptom relief. ${ }^{15}$ In 1974, Robert F. Spetzler (Fig. 5) described utilizing the occipital artery for anastomosis in the event that the STA is unsuitable for use. ${ }^{44}$ Two years later, a report by Norman Chater and Spetzler assessed which portion of the MCA tree provided the best blood flow, determining that the cortical arteries in the area of the angular gyrus, when compared to the tip of the frontal and temporal lobes, were most suitable given their large diameter size and proximity to the STA. ' In addition to assessing anatomical characteristics of EC-IC bypass, Spetzler and Chater also evaluated postoperative blood flow.

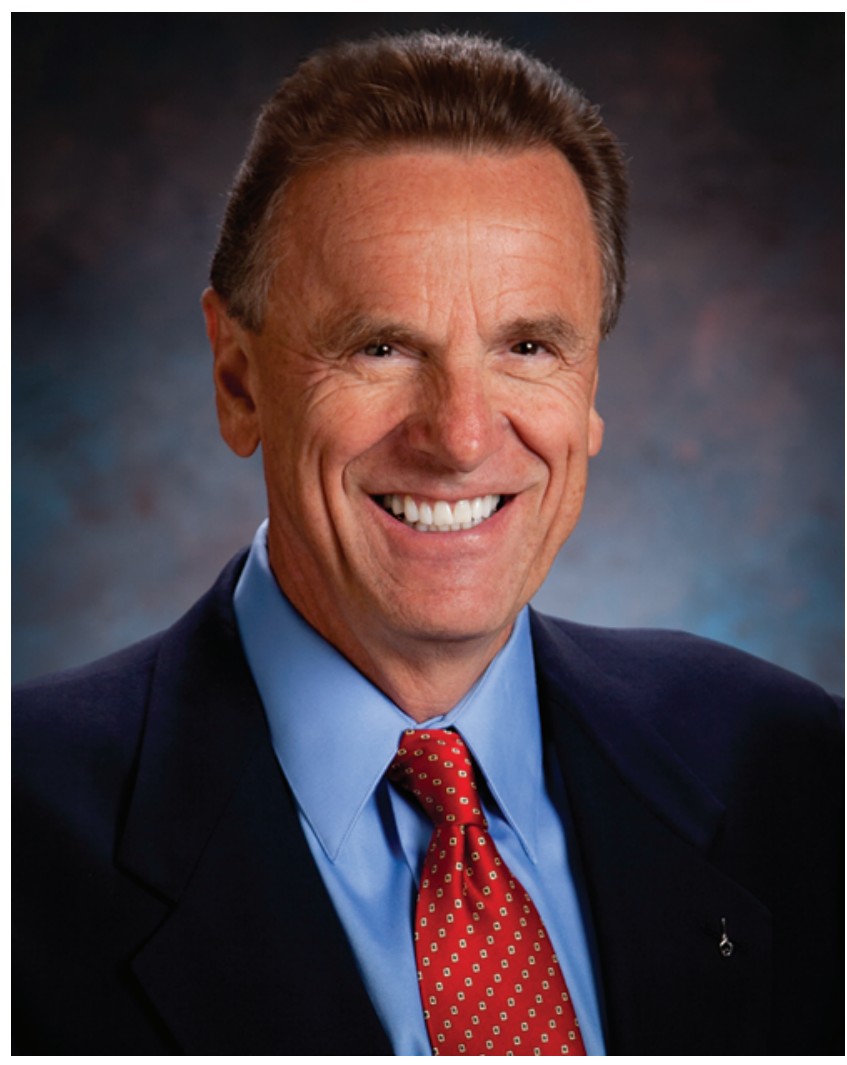

FIG. 5. Portrait of Robert F. Spetzler. Image reproduced with permission from Barrow Neurological Institute at St. Joseph's Hospital and Medical Center.

While flow after STA-MCA bypass is expected to be $8.4 \%$ of the flow from one ICA, vessel diameter was observed to increase $90 \%$ on average. Given that flow is proportional to the fourth power of the vessel radius based on Poiseuille's law, the STA was shown to compensate and carry a greater blood volume when necessary ${ }^{43}$ Also in 1976, a study assessing EC-IC bypass in 65 patients over a 5-year period was published, stating that regional cerebral blood flow (rCBF) must be evaluated in order to determine the best candidates for surgery. The study concluded that ECIC bypass was most beneficial in patients presenting with transient ischemic attacks, prolonged reversible ischemic neurological deficits, and completed strokes with focal, rather than generalized reductions in $\mathrm{rCBF}$. EC-IC bypass was determined to be contraindicated in patients presenting with acute cerebral ischemia. ${ }^{14}$ In 1978, Ausman et al. used a radial artery graft to anastomose the vertebral artery to the posterior inferior cerebellar artery (PICA). ${ }^{16}$ That same year, Sundt et al. demonstrated posterior circulation revascularization by anastomosing the occipital branch of the external carotid artery to the PICA..$^{51}$ Miller and Spetzler, in 1979, successfully anastomosed the middle meningeal artery to the MCA. ${ }^{30}$ A year later, Story et al. performed an ICA-to-MCA bypass with an SV graft. ${ }^{50}$ Spetzler et al. applied EC-IC bypass to patients with intracranial and ICA giant aneurysms, successfully preventing ischemic complications on follow-up. ${ }^{47,48}$ Spetzler also reported a subclavian-to-MCA SV graft procedure ${ }^{45}$ and 
suturing of the STA adventitia to the cortical arachnoid as alternatives to providing cerebral revascularization. ${ }^{46}$ In 1993, development of nonocclusive anastomosis techniques, such as the excimer laser-assisted nonocclusive anastomosis (ELANA) technique, was created by Cornelius Tulleken. The ELANA technique is effective in aiding in the treatment of giant and large ICA aneurysms. Despite resulting in a reduction of perioperative ischemic events, there is a higher risk of postoperative hemorrhage..$^{55,56}$

\section{Clinical Trials}

As STA-MCA bypass and its derivatives rose in popularity, there emerged the need to evaluate the efficacy and safety of this procedure, prompting the start of the International Cooperative Study of Extracranial/Intracranial Arterial Anastomosis (EC/IC Bypass Study) in 1977. Ending in 1985, the study concluded that the anastomosis of the STA to the MCA failed to prevent stroke in patients with symptomatic carotid artery occlusion. ${ }^{9}$ The results of the study generated much criticism. Given advances in PET, the Carotid Occlusion Surgery Study (COSS) was initiated in 2002. A prospective, parallel-group, 1:1 randomized, open-label, blinded-adjudication treatment trial, the COSS was designed to test the hypothesis that STA-MCA anastomosis, when combined with best medical therapy, would reduce the 2-year risk of subsequent ipsilateral ischemic stroke in patients by $40 \%$ when compared to best medical therapy only. ${ }^{35}$ The study was terminated early in 2010 given that the nonsurgical group arrived at an unexpectedly low rate of primary endpoints in spite of the excellent graft patency and improved hemodynamics achieved in the surgical group..$^{35}$ The results of both these studies have significantly narrowed the clinical indications of EC-IC bypass surgery for cerebral revascularization.

In 2014, the results of the Japan Adult Moyamoya (JAM) trial were published. Conducted from 2001 to 2013, this study was a multicenter, prospective, randomized controlled trial that tested the hypothesis that EC-IC bypass can prevent hemodynamic stress and rebleeding in patients with hemorrhagic moyamoya disease when compared to conservative therapy. The JAM trial ultimately showed that EC-IC bypass has preventative benefit and improves patient prognosis 5 years after enrollment. ${ }^{31} \mathrm{~A}$ retrospective study in 2013 published similar findings to the JAM trial, citing the benefit of STA-MCA bypass in improving outcomes in patients with moyamoya disease. ${ }^{1}$

\section{Current Applications}

The utility of EC-IC bypass has become much more limited since the 1980s. Improvements in medical management, the results of landmark trials, and the advent of new technology and endovascular techniques have led to a decrease in the indications for cerebral revascularization. Despite this, current indications for EC-IC bypass include complex intracranial aneurysms in which endovascular coiling or clipping is not viable, artery-encasing skull base tumors, moyamoya disease, and vascular occlusive disease in patients who remain refractory to maximal medical management. ${ }^{15,21-23,39}$ EC-IC bypass is most useful when there is a need to sacrifice a parent artery or its branches, or in cases in which prophylactic bypass is necessary when prolonged temporary occlusion is expected. ${ }^{40,41} \mathrm{~A}$ bypass may be used to decrease the morbidity and mortality rates in patients with cancers involving the ICA, and it serves as an alternative to carotid resection which, on its own, has poor prognosis. ${ }^{5}$

\section{Conclusions}

Human inquiry into vascular anatomy began nearly 5000 years ago with the ancient Egyptians, who were the first to perform blood vessel surgery. Compiled medical knowledge through the time of Galen in both anatomy and physiology prepared later physicians such as Willis, Hallowell, and Abbe to further develop surgical skills for arterial repair while also improving our understanding of occlusive disease and apoplexy. Murphy's introduction of end-to-end anastomosis marked the beginning of the transition period from primitive vascular techniques to the complex microsurgical techniques developed by Yaşargil and others after him. EC-IC bypass was originally utilized for a large variety of procedures, but following several clinical trials, this technique is currently indicated in the treatment of complex aneurysms, invasive tumors, and moyamoya disease in the modern era.

\section{References}

1. Abla AA, Gandhoke G, Clark JC, Oppenlander ME, Velat GJ, Zabramski JM, et al: Surgical outcomes for moyamoya angiopathy at barrow neurological institute with comparison of adult indirect encephaloduroarteriosynangiosis bypass, adult direct superficial temporal artery-to-middle cerebral artery bypass, and pediatric bypass: 154 revascularization surgeries in 140 affected hemispheres. Neurosurgery 73:430-439, 2013

2. Artico M, Spoletini M, Fumagalli L, Biagioni F, Ryskalin L, Fornai F, et al: Egas Moniz: 90 years (1927-2017) from cerebral angiography. Front Neuroanat 11:81, 2017

3. Barker WF: A century's worth of arterial sutures. Ann Vasc Surg 2:85-91, 1988

4. Bobadilla JL: From Ebers to EVARs: a historical perspective on aortic surgery. Aorta (Stamford) 1:89-95, 2013

5. Brisman MH, Sen C, Catalano P: Results of surgery for head and neck tumors that involve the carotid artery at the skull base. J Neurosurg 86:787-792, 1997

6. Bulsara KR, Sukhla S, Nimjee SM: History of bipolar coagulation. Neurosurg Rev 29:93-96, 2006

7. Chater N, Spetzler R, Tonnemacher K, Wilson CB: Microvascular bypass surgery. Part 1: anatomical studies. J Neurosurg 44:712-714, 1976

8. Crowley RW, Medel R, Dumont AS: Evolution of cerebral revascularization techniques. Neurosurg Focus 24(2):E3, 2008

9. EC/IC Bypass Study Group: Failure of extracranial-intracranial arterial bypass to reduce the risk of ischemic stroke. Results of an international randomized trial. N Engl J Med 313:1191-1200, 1985

10. Elhadi AM, Kalb S, Perez-Orribo L, Little AS, Spetzler RF, Preul MC: The journey of discovering skull base anatomy in ancient Egypt and the special influence of Alexandria. Neurosurg Focus 33(2):E2, 2012

11. Engelhardt E: Apoplexy, cerebrovascular disease, and stroke: historical evolution of terms and definitions. Dement Neuropsychol 11:449-453, 2017 
12. Fisher M: Occlusion of the internal carotid artery. AMA Arch Neurol Psychiatry 65:346-377, 1951

13. Friedlaender GE, Friedlaender LK: Saints Cosmas and Damian: patron saints of medicine. Clin Orthop Relat Res 474:1765-1769, 2016

14. Gratzl O, Schmiedek P, Spetzler R, Steinhoff H, Marguth F: Clinical experience with extra-intracranial arterial anastomosis in 65 cases. J Neurosurg 44:313-324, 1976

15. Guzman R, Lee M, Achrol A, Bell-Stephens T, Kelly M, Do HM, et al: Clinical outcome after 450 revascularization procedures for moyamoya disease. Clinical article. J Neurosurg 111:927-935, 2009

16. Hayden MG, Lee M, Guzman R, Steinberg GK: The evolution of cerebral revascularization surgery. Neurosurg Focus 26(5):E17, 2009

17. Hernigou P: Ambroise Paré II: Paré's contributions to amputation and ligature. Int Orthop 37:769-772, 2013

18. Hippocrates, Fischer C: The Corpus: The Hippocratic Writings. New York: Kaplan Publishing, 2008

19. Jacobson JH, Suarez EL: Microsurgery in anastomosis of small vessels. Surg Forum 11:243-245, 1960

20. Jassinowsky A: Die Arteriennaht: Eine ExperimentellChirurgische Studie. Dorpat, Estonia: Druck von C. Mattiesen, 1889

21. Kalani MYS, Elhadi AM, Ramey W, Nakaji P, Albuquerque FC, McDougall CG, et al: Revascularization and pediatric aneurysm surgery. J Neurosurg Pediatr 13:641-646, 2014

22. Kalani MYS, Kalb S, Martirosyan NL, Lettieri SC, Spetzler RF, Porter RW, et al: Cerebral revascularization and carotid artery resection at the skull base for treatment of advanced head and neck malignancies. J Neurosurg 118:637-642, 2013

23. Kalani MYS, Rangel-Castilla L, Ramey W, Nakaji P, Albuquerque FC, McDougall CG, et al: Indications and results of direct cerebral revascularization in the modern era. World Neurosurg 83:345-350, 2015

24. Link TE, Bisson E, Horgan MA, Tranmer BI: Raymond M. P. Donaghy: a pioneer in microneurosurgery. J Neurosurg 112:1176-1181, 2010

25. Lo WB, Ellis H: The circle before Willis: a historical account of the intracranial anastomosis. Neurosurgery 66:7-18, 2010

26. Lougheed WM, Marshall BM, Hunter M, Michel ER, Sandwith-Smyth H: Common carotid to intracranial internal carotid bypass venous graft. Technical note. J Neurosurg 34:114-118, 1971

27. Loukas M, Hanna M, Alsaiegh N, Shoja MM, Tubbs RS: Clinical anatomy as practiced by ancient Egyptians. Clin Anat 24:409-415, 2011

28. Lyons C, Galbraith G: Surgical treatment of atherosclerotic occlusion of the internal carotid artery. Ann Surg 146:487498, 1957

29. Menzoian JO, Friedman SG: Robert Abbe: The life and times of a 19th century surgeon. J Vasc Surg 66:1290-1292, 2017

30. Miller CF II, Spetzler RF, Kopaniky DJ: Middle meningeal to middle cerebral arterial bypass for cerebral revascularization. Case report. J Neurosurg 50:802-804, 1979

31. Miyamoto S, Yoshimoto T, Hashimoto N, Okada Y, Tsuji I, Tominaga T, et al: Effects of extracranial-intracranial bypass for patients with hemorrhagic moyamoya disease: results of the Japan Adult Moyamoya Trial. Stroke 45:1415-1421, 2014

32. Mohr JP, Caplan LR, Kistler JP: C. Miller Fisher: an appreciation. Stroke 43:1739-1740, 2012

33. Munster AB, Thapar A, Davies AH: History of carotid stroke. Stroke 47:e66-e69, 2016

34. Nylen CO: The microscope in aural surgery, its first use and later development. Acta Otolaryngol Suppl 116:226-240, 1954

35. Powers WJ, Clarke WR, Grubb RL Jr, Videen TO, Adams HP Jr, Derdeyn CP: Extracranial-intracranial bypass surgery for stroke prevention in hemodynamic cerebral ischemia: the Carotid Occlusion Surgery Study randomized trial. JAMA 306:1983-1992, 2011

36. Rich NM: Vascular trauma historical notes. Perspect Vasc Surg Endovasc Ther 23:7-12, 2011

37. Rickard RF, Hudson DA: A history of vascular and microvascular surgery. Ann Plast Surg 73:465-472, 2014

38. Safavi-Abbasi S, Brasiliense LBC, Workman RK, Talley MC, Feiz-Erfan I, Theodore N, et al: The fate of medical knowledge and the neurosciences during the time of Genghis Khan and the Mongolian Empire. Neurosurg Focus 23(1):E13, 2007

39. Sanai N, Zador Z, Lawton MT: Bypass surgery for complex brain aneurysms: an assessment of intracranial-intracranial bypass. Neurosurgery 65:670-683, 2009

40. Sekhar LN, Nelson PB: A technique of clipping giant intracranial aneurysms with the preservation of the parent artery. Surg Neurol 20:361-368, 1983

41. Sekhar LN, Patel SJ: Permanent occlusion of the internal carotid artery during skull-base and vascular surgery: is it really safe? Am J Otol 14:421-422, 1993

42. Singh V: Sushruta: The father of surgery. Natl J Maxillofac Surg 8:1-3, 2017

43. Spetzler R, Chater N: Microvascular bypass surgery. Part 2: physiological studies. J Neurosurg 45:508-513, 1976

44. Spetzler R, Chater N: Occipital artery-middle cerebral artery anastomosis for cerebral artery occlusive disease. Surg Neurol 2:235-238, 1974

45. Spetzler RF, Rhodes RS, Roski RA, Likavec MJ: Subclavian to middle cerebral artery saphenous vein bypass graft. J Neurosurg 53:465-469, 1980

46. Spetzler RF, Roski RA, Kopaniky DR: Alternative superficial temporal artery to middle cerebral artery revascularization procedure. Neurosurgery 7:484-487, 1980

47. Spetzler RF, Roski RA, Schuster H, Takaoka Y: The role of EC-IC in the treatment of giant intracranial aneurysms. Neurol Res 2:345-359, 1980

48. Spetzler RF, Schuster H, Roski RA: Elective extracranialintracranial arterial bypass in the treatment of inoperable giant aneurysms of the internal carotid artery. $\mathbf{J}$ Neurosurg 53:22-27, 1980

49. Starzl TE, Porter KA, Francavilla A: The Eck fistula in animals and humans. Curr Probl Surg 20:687-752, 1983

50. Story JL, Brown WE Jr, Eidelberg E, Arom KV, Stewart JR: Cerebral revascularization: common carotid to distal middle cerebral artery bypass. Neurosurgery 2:131-135, 1978

51. Sundt TM Jr, Whisnant JP, Piepgras DG, Campbell JK, Holman CB: Intracranial bypass grafts for vertebral-basilar ischemia. Mayo Clin Proc 53:12-18, 1978

52. Szczerbo-Trojanowska M, Jargiełło T, Drelich-Zbroja A: Management of carotid stenosis. History and today. J Ultrason 13:6-20, 2013

53. Thanapal S, Duvuru S, Sae-Ngow T, Kato Y, Takizawa K: Direct cerebral revascularization: extracranial-intracranial bypass. Asian J Neurosurg 13:9-17, 2018

54. Uluç K, Kujoth GC, Başkaya MK: Operating microscopes: past, present, and future. Neurosurg Focus 27(3):E4, 2009

55. van Doormaal TPC, Klijn CJM, van Doormaal PTC, Kappelle LJ, Regli L, Tulleken CAF, et al: High-flow extracranial-to-intracranial excimer laser-assisted nonocclusive anastomosis bypass for symptomatic carotid artery occlusion. Neurosurgery 68:1687-1694, 2011

56. van Doormaal TPC, van der Zwan A, Verweij BH, Langer DJ, Tulleken CAF: Treatment of giant and large internal carotid artery aneurysms with a high-flow replacement bypass using the excimer laser-assisted nonocclusive anastomosis technique. Neurosurgery 62 (6 Suppl 3):1411-1418, 2008

57. Vilela MD, Newell DW: Superficial temporal artery to middle cerebral artery bypass: past, present, and future. Neurosurg Focus 24(2):E2, 2008 
58. Voorhees JR, Cohen-Gadol AA, Laws ER, Spencer DD: Battling blood loss in neurosurgery: Harvey Cushing's embrace of electrosurgery. J Neurosurg 102:745-752, 2005

59. Wiltse LL, Pait TG: Herophilus of Alexandria (325-255

B.C.). The father of anatomy. Spine (Phila Pa 1976)

23:1904-1914, 1998

60. Yaşargil MG: Editorial. Personal considerations on the history of microneurosurgery. J Neurosurg 112:1347, 2010

\section{Disclosures}

The authors report no conflict of interest concerning the materials or methods used in this study or the findings specified in this paper.

\section{Author Contributions}

Conception and design: Kalani, S Soldozy, Costello. Acquisition of data: S Soldozy, Costello, K Soldozy. Analysis and interpretation of data: S Soldozy, Costello. Drafting the article: S Soldozy, Costello. Critically revising the article: Norat, Sokolowski, Park. Reviewed submitted version of manuscript: all authors. Approved the final version of the manuscript on behalf of all authors:

Kalani.

\section{Correspondence}

M. Yashar S. Kalani: University of Virginia Health System, Charlottesville,VA.kalani@virginia.edu. 